\title{
Effects of Exogenous Regulation of Ethylene and Abscisic Acid on Grain-Filling and Endosperm PCD of Wheat Under Drought Stress After Anthesis
}

\section{Chao Li}

Shihezi University

\section{Xiangchi Zhang}

Shihezi University

\section{Wenting Guo}

Agricultural and rural Bureau ,Tekes County ,Bureaulli Kazak Autonomous Prefecture,Xinjiang

\section{Kaiyong Fu}

Shihezi University

\section{Cheng Li}

Shihezi University

Chunyan Li ( $\sim$ lichunyan82@aliyun.com)

Shihezi University

\section{Research Article}

Keywords: Drought, Endosperm cell, ethylene, Abscisic acid, Programmed cell death, Triticum aestivum L.

Posted Date: August 27th, 2021

DOI: https://doi.org/10.21203/rs.3.rs-829064/v1

License: (1) This work is licensed under a Creative Commons Attribution 4.0 International License. Read Full License 


\section{Abstract}

Although studies have shown that grain-filling and programmed cell death of wheat endosperm are affected by drought stress, which is closely related to ethylene and abscisic acid.The mechanism of ethylene and abscisic acid regulate grain-filling and endosperm PCD under drought stress is remains unclear. In this study, we regulated the production of ethylene and abscisic acid in wheat grains under drought stress at filling stage by chemicals. The results showed that spraying ethylene synthesis inhibitor enhanced endosperm cell viability, delayed nuclear deformation, and decreased ACC content. Compared with the CK, the CN significantly decreased the DNA hydrolase activity and significantly increased the DNA content. In addition, the $\mathrm{CN}$ treatment reduced the expression of four genes related to ethylene receptors (ers1, ers2 etr1, etr2) and increase the expression of dad1. Under CN treatment, the process of endosperm PCD was delayed, the duration of high grouting rate was prolonged, and the grain weight was increased, in contrast, the opposite result was obtained after spraying abscisic acid synthesis inhibitor. The production of abscisic acid and ethylene in grains determines the fate of endosperm cells. A new model of artificial regulation of abscisic acid and ethylene, delaying endosperm PCD process and increasing grain weight under post-anthesis drought was proposed.

\section{Introduction}

Wheat is the second most important food crop, providing calories and nutrients for up to one third of the world population ${ }^{1}$. But, nearly $50 \%$ of the world wheat growing area (230 million hectares) is affected by moisture deficit stress ${ }^{2}$. The probability of wheat yield being below the long-term average is greater than $80 \%$ in the event of an exceptional drought ${ }^{3}$. Drought stress can seriously affect the growth and development of wheat, resulting in a variety of physiological and biochemical damage, such as leaf stomatal tissue closure, photosynthesis and transpiration decreased, growth and development inhibited, the production of oxidation, changes in hormone levels $s^{4,5}$. In the world's major wheat growing areas, surface evaporation often exceeds average precipitation. Although drought stress may affect the growth of wheat during whole growth period, the developmental stages of heading, flowering and grain filling stages were more sensitive to drought ${ }^{6}$. The drought stress to the heading stage and grain-filling phases were called "end-stage drought" The end-stage drought in wheat production is a common phenomenon which is an important reason for the large decline in wheat yield $^{9-11}$. Post-anthesis drought stress usually shortens wheat grain filling and reduces the filling rate ${ }^{12,13}$. Faroogreported that milddrought after flowering caused a $1-30 \%$ reduction in wheat yield ${ }^{14}$. With the global climate change in the near future, the impact of drought on wheat production may continue to increase ${ }^{15}$.

PCD, the highly regulated dismantling of cells, occurs during the development of a living organism ${ }^{16}$. It is an active cell death process controlled by specific genes and also a manifestation of the plant reaction/adaptation to the environment ${ }^{17}$. In plants, PCD is ubiquitous and indispensable in the whole process of cell growth and survival, such as the development of tubular cells ${ }^{18}$, aleurone cells $^{19}$, and root cap cells ${ }^{20}$. In wheat, the endosperm cells are the main storage organ that account for $80-85 \%$ of the grain weight ${ }^{21}$. Olsen et al. in 1998, found that endosperm cells are gradually synthesize storage starch and protein particles during development ${ }^{22}$. As they synthesize storage starch and protein, endosperm cells also initiate a programmed cell death. Finally, all endosperm cells died except aleurone cells. Although PCD is an active process and controlled by genes, there are many external factors that can induce and accelerate PCD in plants. Fan et al.in 2013, and Cheng et al. in 2016, reported that water-logging accelerated accumulation of reactive oxygen species in wheat endosperm cells, resulting in chromatin condensation, nuclear membrane breakdown, accelerated PCD processes and reduced grain weight ${ }^{23,24}$. Panda et al. in 2008, reported that aluminum ions can change the mitochondrial structure of tobacco suspension cells, release cytochrome c, cause the fragmentation of genomic DNA ${ }^{25}$. Chen et al. in 2009, found that salt stress could accelerate the programmed death of rice root tip cells ${ }^{26}$. Our previous study showed that post-anthesis drought stress led to the advancement of the PCD process in the wheat endosperm ${ }^{27}$.

The PCD of cereal crop's endosperm is greatly influenced by endogenous hormones ${ }^{28}$. Previous studies have shown there is the interaction among the hormones, which constitute a very fine and complex regulatory network together with the external environment and their own developmental programs ${ }^{29-31}$. Furthermore, the main endogenous hormones ethylene and abscisic acid had significant effect on the endosperm PCD and grain filling process of cereal crops. The activation of PCD and the increase of nuclease activity in maize and wheat endosperm were accompanied by ethylene production ${ }^{32-34}$. It has been found that high amounts of ACC content and low expression of ethylene receptors are important for endosperm prone to $\mathrm{PCD}^{27}$. Bethke reported that ABA can inhibit PCD in barley aleurone laye ${ }^{35}$. By spraying abscisic acid on rice during grain filling, the ethylene content in grains was reduced significantly, however, the endosperm cell division rate, maximum cell number, grain filling rate and grain weight was increased ${ }^{36,37}$. 
Although there have been many studies on the PCD of wheat endosperm, the mechanism by which ethylene and abscisic acid regulate the PCD of endosperm and grain-filling under drought stress is remains unclear. Based on the previous research of our research group, in this study, ethylene and ABA synthesis inhibitors were sprayed on wheat ears under post-anthesis drought. Characteristic changes from PCD and grain filling will provide a new theoretical basis for artificial intervention in drought hazards.

Many researches have been done on the PCD of wheat endosperm, however, the regulation mechanism of ethylene and ABA on endosperm PCD, especially the PCD progress subjected to the drought stress under post-anthesis remains unclear. In this study, by spraying ethylene and ABA synthesis inhibitors on wheat, we investigated the process of endosperm PCD and examined the role of ethylene and $A B A$ in regulating endosperm $P C D$ under post-anthesis drought. The objective of present study was to increase understanding about alleviating the damage of drought stress on wheat production.

\section{Results}

\section{Grain weight and grain-filling characteristic parameters}

Grain weight increased across sampling date (Figure 1). At 5-10 DPA, there was no significant difference among three treatments. The main differences between the three different treatments are concentrated at 15-35DPA. The effects of CN treatment on grain weight were mainly concentrated in the spraying period (15 DPA) and the middle-late filling period (25-35 DPA). The grain weight in these two periods was significantly higher than that of CK. The FU treatment significantly increased the grain weight during the spraying period (15 DPA), but significantly reduced the grain weight in the later stage of grain-filling (30-35 DPA). This result indicates that the grain weight was significantly enhanced by $\mathrm{CN}$ treatment and declined by FU treatment.

According to the grain-filling parameters, the grain-filling process of wheat was well simulated using logistic equations. As can be seen from table 2 , the results fit the curve with high reliability, with an $\mathrm{R}^{2}$ coefficient of determination values above 0.999 . Compared with $\mathrm{CK}$ treatment, $\mathrm{CN}$ significantly increased the maximum theoretical grain weight by $7.5 \%$ and $\mathrm{FU}$ treatment significantly reduced the maximum theoretical grain weight by $9.5 \%$. Furthermore, $\mathrm{CN}$ treatment significantly prolonged the active grouting period and the effective grouting period, by $12.2 \%$ and $7.7 \%$, respectively, compared with CK. There was no significant change in the active grouting period between the FU and CK treatment, but the effective grouting period was significantly shortened by $4.5 \%$. The maximum grouting rate under CK treatment appeared at an earlier time point than CK treatment. And the grain weight at the maximum grouting rate was significantly higher than that of CK treatment. While the opposite tendency was obtained under FU treatment.

\section{Characteristics of grain-filling stage}

The whole grain-filling process were subdivided into early, middle and late stages according to the standard logistic curve. The results were shown in table 3. From the perspective of the duration of three periods, the effects of $\mathrm{CN}$ treatment on the grouting process were mainly concentrated in the middle and end stages. $\mathrm{CN}$ treatment significantly extended the duration of the middle and late stages by $12.1 \%$ and $12.1 \%$, respectively. The FU treatment significantly shortened the early duration by $9.6 \%$, and had no significant effect on the duration of the middle and end stages. Compared with CK, the mean grain-filling rate of CN was significantly increased by $9.5 \%$ in the early, significantly decreased by $4.2 \%$ in the middle and no significant difference in the late. The mean grain-filling rate of FU was significantly lower than that of CK treatment in the middle and late stages, with a decrease of $8.1 \%$ and $9.1 \%$, respectively. The increased grain weight of $\mathrm{CN}$ treatment in the early, middle and late stages increased significantly by $32.7 \%, 7.3 \%$, and $7.4 \%$ respectively, compared with CK. On the contrary, the increased grain weight of FU was significantly lower than that of CK in the early, middle and late stages, which were reduced by $9.6 \%, 9.6 \%$, and 9.6 respectively.

\section{Endosperm cell activity}

In order to observe the PCD process of wheat endosperm under different treatments, the viability of endosperm cells in the cross-section of grain was detected by Evan's Blue staining (Fig. 2). The selective permeability of dead cell membrane became worse and it is colored blue, however, living cells are not colored. The results showed that the endosperm of CK, CN and FU treatments were not stained at the initial filling stage (before $10 \mathrm{DPA}$ ), and the staining sites were mainly concentrated on the pericarp (Fig. 2, A1-C1). The endosperm stained was initially observed at 15 DPA (Fig. 2, A2-C2). With grain filling, the number of stained cells increased gradually, and the whole endosperm was stained at the later stage of grain filling (Fig. 2, A3-C3, A4-C4). There was no obvious difference among three treatments at 10 DPA (Fig. 2, A1-C1). However, from 15 to 25 DPA the number of stained cells was the highest in FU treatment, followed by CK and CN (Fig. 2, A2-C2, A3-C3, A4-C4). 
DAPI fluorescent dyes have strong specificity and sensitivity to the nucleus and chromosomes in cells and it exhibits blue fluorescence when combined with DNA. DAPI can stain nuclei regardless of whether or not the cells undergo death. Therefore, the morphological changes of the endosperm nuclei can be observed by DAPI staining. The wheat kernels at different developmental stages under various treatments were sectioned and stained. The results are shown in Figure 2. It was observed that some of the nuclei in CK treatment were deformed at 25 DPA, and the FU had more deformed nuclei than the CK. However, most of the nuclei remain small and normally spherical shape under CN, only a few deformed nuclei were detected (Fig. 3, A1-A3). At 30 DPA, almost all nuclear morphologies changed, of which FU was the most varied, followed by CK and CN treatment (Fig. 3, B1-B3). The results indicated that CN was helpful to slow down the process of nuclear morphological changes of endosperm, while the FU accelerated the process.

\section{Ultrastructure observation of endosperm cells under different treatments}

In order to further explore the influence of different treatments on the nuclear morphological changes of endosperm, ultrathin sections of wheat endosperm at different development stages were made and observed by transmission electron microscopy (TEM). At 15 DPA, the CK treatment exhibited that the heterochromatin increased in the nucleus, nucleoli disappeared, and the nuclear edge was not smooth (Figure. 4, A1). The nuclei in endosperm cells were normal with evident nucleoli in CN (Figure. 4, A2). And the nucleus morphology of FU was similar to that of CK (Figure. 4, A3). At 20 DPA, the CK treatment showed that the nuclei appeared obvious pits, nucleoli disappeared, nucleoli concentrated, and the morphology was irregular (Figure. 4, B1). Under CN condition, the endosperm cells still had nucleoli, however, the edge of the nucleus was not smooth, with more pits. The nucleus were inlaid between starch granules and exhibited the irregular morphology (Figure. 4, B2). In contrast, no intact nuclei were observed in endosperm cells of FU treatment and the nuclear debris were found between starch granules (Figure. 4, B3).

\section{Effects of different treatment on the number of endosperm nuclei}

The PCD process was accompanied by the nuclear disintegration. In order to observe the influence of different treatments on the number of endosperm nuclei, we counted the endosperm nuclei at different sampling stages. The period of rapid proliferation of endosperm cell nuclei was 5 between 10 DPA. From 20 to 30 DPA, it was the period of rapid decline of the number of endosperm nuclei. There was no significant difference in the number of endosperm cells among three treatments at 5, 30 and 35 DPA, respectively. The number of endosperm cells were greater in CN and CK than in FU (Figure 5, note the difference was significant between CK and FU). At 25 DPA, the number of endosperm cells in CN was significantly higher than that in CK and FU (Figure 5, note the difference was not significant between $\mathrm{CK}$ and FU). This result suggested that the number of endosperm nuclei could be significantly increased by spraying with cobalt nitrate, while it could be significantly decreased by spraying with fluridone.

\section{DNA content and DNA hydrolase activity in wheat kernels}

The degradation of endosperm nucleus could be confirmed by measuring the change of total DNA content in grain. The DNA content in the grain varied depending on sampling time and different treatment (Figure 6A). The variation trend of DNA content in three treatments was similar, showing a single peak. The DNA content under CK and FU treatments was gradually increased and reached its peak at 20 DPA. However, the peak time of CN treatment was later, at 25 DPA. It should be noted that at the early stage of grain filling (5 DPA), whereas there was no significant difference among three treatments. From 25 to 35 DPA, the CN treatment had the greatest DNA content among the treatments.

Degradation of genomic DNA, often accompanied by an increase in DNA hydrolase activity. As shown in Figure 6B, the activity of DNA hydrolase showed the similar pattern among different treatments. The DNA hydrolase activity in CK and FU treatments gradually increased from 5 to 15 DPA, and increased suddenly to the peak at 20 DPA and then decreased. The DNA hydrolase activity was greater in FU than in CK and CN. However, the CN reached the maximum at 25 DPA and then decreased gradually, maintaining the greatest DNA hydrolase activity among three treatments between 25 to 35 DPA. Combined with the above anatomical results, the period of 15 to 20 DPA is the rapid growth period of PCD and also the key period of grain filling. Meanwhile, the nuclease activity of CK and FU reaches its peak rapidly with the rate of change greater than $\mathrm{CN}$, while $\mathrm{CN}$ reaches its peak at $25 \mathrm{DPA}$. These results suggest that the $\mathrm{CN}$ treatment can slow down genomic DNA degradation during the critical grouting period (15-20d). Spray application of fluridone treatment resulted in an increase in nuclease activity and accelerated degradation of genomic DNA.

\section{$A C C$ and $A B A$ content in wheat kernels}


1-Aminocyclopropane-1-carboxylic acid (ACC), a precursor of ethylene, its variation trend can reflect the fluctuation of ethylene content. As shown in Figure 7A, the ACC content in the grain varied depending on sampling date and different treatment. From5 to 10 DPA, the ACC content was declined in $\mathrm{CN}$, on the contrary, the content of ACC was rapidly increased in CK and FU treatment. The FU treatment had the highest ACC content and CN had the lowest ACC content among three treatments from 10 to 30 DPA (Figure 7B).

As shown in Figure 7B, the ABA content in grains of the three treatments had a consistent trend in different periods, showing a single peak. The CK and $\mathrm{CN}$ reached the maximum value at $25 \mathrm{DPA}$, while the FU reached the maximum value at $20 \mathrm{DPA}$. There was no significant difference in $\mathrm{ABA}$ content between $\mathrm{CK}$ and $\mathrm{CN}$, but under $\mathrm{FU}$ treatment it was significantly lower than $\mathrm{CK}$ and $\mathrm{CN}$ treatments from 10 to 35 DPA. The results showed that spraying cobalt nitrate had no significant effect on ABA content in wheat grains, however, spraying fluridone could significantly reduce ABA content in wheat grains.

\section{Genes involved in ethylene receptors and PCD}

The relative expression pattern of four genes (ers1, ers2, etr1, etr2) encoding ethylene receptors, and one gene (dad1) involved in PCD were shown Fig.8. The expression patterns of the four ethylene receptor genes were similar, and all had lower expression levels in the mid-filling $₫ 15-25 D P A \rrbracket$ which was the rapid period of $P C D$. The relative expression of the four receptor genes was significantly higher in $\mathrm{CN}$ group than in the CK group at all times, except for 5 DPA. In contrast, the opposite phenomenon was observed in FU group. The expression of the dad1 increases gradually as the grain filling, reaching a maximum at 35 DPA. Compared with the CK treatment, the relative expression of dad1 was significantly increased in the $\mathrm{CN}$ treatment. The opposite results were observed in the FU group, except at 5, 30, and 35 DPA. The results showed that spraying cobalt nitrate significantly increased the relative expression of the ethylene receptor genes and the PCD repressor gene, and spraying fluridone significantly decreased their expression.

\section{Relationship between DNA content, ABA content and grouting rate in wheat grains under different treatments.}

Correlation analysis showed that there was a significant positive correlation between grain filling rate to DNA content and ABA content under the three treatments, respectively (Table.4). The correlation coefficient between grain filling rate and DNA content under CN treatment was 0.937 . Furthermore, there was a significant positive correlation between ABA content and DNA content in the three treatments, and the correlation coefficients were all greater than 0.8 .

\section{Discussion}

On the basis of growth phases, grain development has been divided into three phases: grain enlargement, grain filling and physiological maturity ${ }^{38}$. Endogenous hormones, especially ethylene and ABA, have a significant effect on endosperm PCD and grain filling ${ }^{13,39}$. However, the mechanism by which ETH affect grain filling in wheat is unclear. It was found that ethylene may be used as a signal to promote the decomposition of storage compound, such as promoting the expression of a-amylase ${ }^{40}$. Naik and Mohapatra sprayed rice panicles with inhibitors of ethylene synthesis at the early stage of grain filling, which significantly increased the activity of sucrose synthase in the grains ${ }^{41,42}$. This study found that after spraying the ethylene synthesis inhibitor, the ethylene level in the grain decreased significantly. Although the maximum filling rate decreased significantly, the average filling rate did not change significantly. Interestingly, the active filling period and effective filling period of the grains were significantly prolonged, and the grain weight increased significantly. The accumulation of nutrients in endosperm cells during grain development is also the stage of programmed endosperm cell death ${ }^{27}$. Yang reported that cytokinins play an important role in the division of endosperm cells ${ }^{43}$, and ethylene accelerates the decomposition of cytokinins ${ }^{44}$. This study found that spraying ethylene synthesis inhibitors significantly increased the number of endosperm cell nuclei, and significantly increased the average grain-filling rate in the early stage. Therefore, we speculate that the regulatory effect of ethylene on grain filling may be reflected in two aspects: (i) inhibiting the division of endosperm cells to limit the size of the library, (ii) accelerating the death of endosperm cells and shortening the filling time.

In the actual test, we found that after the seeds were picked, the seeds were in a state of injury, and the stress response of the plant would cause a large amount of ethylene in the seeds in a short period of time, which was of great interference to our study of endosperm cell PCD ${ }^{45-47}$. ACC is a precursor of ethylene synthesis, and the level of ACC content in organisms directly determines the production of ethylene ${ }^{48,49}$. Therefore, in the actual experiment, we measured the ACC content in seeds to indirectly reflect the level of ethylene in the actual biological process. Ethylene plays an important regulatory role in plant growth and development and in response to stress. Under adverse conditions, the synthesis of ethylene in plants can lead to degradation of proteins and nucleic acids, lipid membrane oxidation and membrane damage ${ }^{50,51}$. Ethylene could be produced in the early development of wheat and corn grains, and 
exogenous ethylene could induce endosperm genomic DNA degradation and accelerate programmed endosperm cell death ${ }^{32,33}$. Ethylene promotes $\mathrm{Ca}^{2+}$ flow in cells and enhances endonuclease activity, leading to genomic DNA degradation ${ }^{52,53}$. The ethylene response, in turn, depends on the regulation of ethylene receptors in the downstream pathway, and the ethylene receptor, a negative regulator of the ethylene pathway, becomes inactive upon binding to ethylene ${ }^{54}$. There are five ethylene receptors in plants, and when any one of the ethylene receptors is mutated, the response of the plant to ethylene does not change significantly. However, when all five receptor genes are mutated, the plant will show a constitutive response to ethylene ${ }^{49}$. The results of this study show that the overall expression of ethylene receptors decreases in the middle of grain filling (15-25 DAP), indicating that the threshold of ethylene required to induce PCD in endosperm cells decreases. This stage is the period of rapid programmed cell death in the endosperm, suggesting that low expression of the ethylene receptor is an important factor in the induction of PCD in endosperm. Water stress can cause a rapid accumulation of $A C C$ and a large release of ethylene ${ }^{55,56}$. Suppressing ethylene levels in transgenic maize using gene silencing technology can significantly improve maize yield under drought conditions ${ }^{57}$. The present results showed that the expression of ethylene receptors was up-regulated in the late stage and the level of ACC in the wheat grains was significantly decreased by spraying the ethylene synthesis inhibitor. This indicated that spraying with an ethylene synthesis inhibitor not only inhibited the production of ethylene, but also increased the ethylene threshold level required for programmed cell death to occur in the endosperm. Thus it inhibited the nuclease activity in wheat seeds and resulted in delaying and weakening the fragmentation of genomic DNA in wheat seeds. Finally, the process of endosperm PCD was retarded.

ABA can regulate the formation and development of plant seeds and activate the resistance of plants to abiotic stress ${ }^{58}$. This study found that $A B A$ content and ethylene receptor gene expression decreased significantly after spraying with an $A B A$ synthesis inhibitor, but $A C C$ content increased significantly. $A B A$ is a negative regulator of ethylene synthesis and function ${ }^{59}$. $A B A$ is not directly involved in PCD development, but ABA biosynthetic pathways and signal perception alter ethylene biosynthesis and thus affect PCD development ${ }^{60}$. Genetic analysis has also revealed that the ABA signaling pathway antagonizes the ethylene signaling pathway to regulate plant growth and development ${ }^{61,62}$. This suggests that, on the one hand, $A B A$ can regulate the endosperm PCD process by inhibiting the synthesis of ethylene during synthesis and perception of signals, and on the other hand, it can also interfere with the downstream pathway of ethylene and thus interfere with the role of ethylene. Both maize ABA-deficient plants and the application of ethylene glycol to wild-type maize resulted in an early onset of DNA fragmentation ${ }^{59}$. When wild-type plants were sprayed with ABA inhibitors, ethylene levels increased significantly and DNA fragmentation arrived earlier. As one would expect, we found a number of phenomena associated with PCD advance after spraying ABA synthesis inhibitor on wheat plants, including (i) the activity of nuclease in grain increased and its peak reached earlier; (ii) DNA content decreased; (iii) endosperm cell viability decreased; (iv) the maximum number of endosperm cells decreased; $(v)$ the rate of nuclear deformation increased, and the endosperm PCD process accelerated. Additionally, ABA was found to inhibit PCD in germinating barley and rice seed aleurone cells ${ }^{63}$. Furthermore, ABA plays an important role in suppressing $\mathrm{Ca}^{2+}$ in the aleurone cells ${ }^{64}$. Excessive concentrations of $\mathrm{Ca}^{2+}$ in the cytoplasm can directly activate DNase and RNase activities, leading to the occurrence of programmed cell death ${ }^{65}$. The increase in $\mathrm{Ca}^{2+}$ is induced by ethylene, which accelerates programmed cell death during hypoxia-induced aeration of maize root tissue formation. Cytochrome $\mathrm{C}$ release can induce PCD in plant cells ${ }^{66}$. The release of cytochrome $C$ from mitochondria was found to induce PCD in plant cells, which in turn was induced by $\mathrm{Ca}^{2+}$ in the cytoplasm ${ }^{67}$. In addition, $\mathrm{Ca}^{2+}$ is induced by abiotic stresses, such as drought, and is involved in signal transduction and regulation as a second messenger in the cell ${ }^{68}$. Therefore, we speculate that, on the one hand, ABA can regulate the endosperm PCD process by influencing the level of cytoplasmic $\mathrm{Ca}^{2+}$ and thus the intracellular nuclease activity; on the other hand, it can regulate the endosperm PCD process by influencing the level of cytoplasmic $\mathrm{Ca}^{2+}$ and thus the mitochondrial membrane permeability and inhibit or release cytochrome c.

Accompanying increased ABA content and decrease ethylene content in wheat grain, grain filling rate and yield increased under moderate drought. In response to severe drought stress, wheat grain grouting rate and yield decreased, accompanying significantly increased $A B A$ and ethylene content ${ }^{13}$. It has been shown that the rapid development of endosperm PCD occurred during the maximum grain filling rate, and the extension of endosperm PCD process was conducive to the increase of grain weight ${ }^{27}$. In this study, it was found that there was no significant difference in ABA content between the control treatment and the cobalt nitrate spraying group. However, the ACC content of the control was significantly higher than that of the cobalt nitrate spraying group, and the endosperm PCD process was intensified. This indicated that drought stress disrupted the balance between ethylene and ABA in plants, and ethylene content increased significantly even though ABA content increased. The antagonistic effect of ABA on ethylene weakened, which leading to accelerated endosperm PCD process, insufficient grain filling, premature maturation, and decreased yield. The higher ABA

Page 6/16 
content and the lower ethylene content in the seeds can help to delay the endosperm PCD process and alleviate the harm caused by drought stress.

Dad1 is a programmed cell death suppressor gene ${ }^{69}$. It has been shown that the expression of $d a d 1$ is low in senescent tissues and high in young tissues of corn and cotton ${ }^{70}$. Overexpression of the dad 1 in wheat and soybean can improve plant resistance, which can effectively delay senescence and plant death caused by abiotic and biotic stresses ${ }^{71}$. In the present study, it was found that spraying cobalt nitrate significantly increased the expression of the dad1 gene, meanwhile, the endosperm PCD was delayed. In contrast, the expression of the dad1 gene was reduced and the endosperm PCD was accelerated under FU treatment. In addition, at 35 DPA, we observed a high expression of dad1. By this time, most of the endosperm cells had already died, and the high expression of dad1 in the seeds may be present in the embryonic cells to protect the high activity of the embryonic tissue cells.

Additionally, it should be mentioned that the changes in intracellular DNA content are related to the endoploidy of the nucleus ${ }^{72}$. Previous studies have reported that endopolyploidy is widespread in the organs of angiosperms, such as the endosperm cells of maize $\mathrm{e}^{73,74}$. It has been found that environmental stresses affect the endopolyploidy process and alter the level of endopolyploidy in plant cells ${ }^{75}$. At the beginning of drought stress, it was observed that the number of cells involved in cell division in maize endosperm decreased rapidly and the number of cells involved in nuclear replication increased gradually, but this phenomenon was inhibited at the end of drought ${ }^{76}$. Moreover, ABA can affect the cellular cycle, hindering the progression of the nuclear cycle and contributing to increased ploidy ${ }^{77-79}$. Although our study did not cover this part,in this study, there was a significantly positive correlation between grain $A B A$ content and DNA content. It led to the questions, whether the changes in ABA content under the three treatments would affect endosperm intracellular ploidy and whether it was related to endosperm PCD? Further exploration of these problems will play an important role in further understanding the mechanism of endosperm PCD under drought stress.

\section{Conclusion}

The process of wheat grain filling and endosperm PCD are regulated by the endogenous hormones ethylene and abscisic acid. Decreasing the ethylene level of grains by chemical means can delay the endosperm PCD process, increase the effective filling time, and further increase the grain weight. Decreasing the level of abscisic acid in the grains will induce an increase in the ethylene content, thereby accelerating the endosperm PCD process, reducing the grain-filling rate and effective filling time. Hence, the grain weight was reduced. The results of this study could provide a theoretical basis for adopting artificial intervention measures in wheat production to alleviate the damage caused by external drought stress, and also provide a new idea for the cultivation of drought-resistant, high-yield and high-quality wheat varieties.

\section{Materials And Methods Ethics statement}

The authors declare that all methods were performed in accordance with the relevant guidelines and regulations. The test varieties were provided by the Key Laboratory of Oasis Eco-agriculture, Xinjiang Production and Construction Group. We obtained permission from the Key Laboratory of Oasis Eco-agriculture, Xinjiang Production and Construction Group to use these varieties.

\section{Experimental site and cultivation methods}

Winter wheat (Triticum aestivum L.) cultivar 'Xindong 22' was planted at the Shihezi University experiment station, Xinjiang, China $\left(44^{\circ} 17 \bigotimes \mathrm{N}, 86^{\circ} 03 \mathrm{E}\right)$. Xindong 22 is an early maturing cultivar, requiring about $267 \mathrm{~d}$ to reach maturity. The soil is gray desert soil (Calcaric Fluvisol). Fertility status of the $0-20 \mathrm{~cm}$ soil depth were as follows:organic matter $16.7 \mathrm{~g} / \mathrm{kg}$, alkaline decomposition nitrogen $69 \mathrm{mg} / \mathrm{kg}$, fast-acting phosphorus $18 \mathrm{mg} / \mathrm{kg}$, fast-acting potassium $216 \mathrm{mg} / \mathrm{kg}$. The plots had previously been cropped to soybean (Glycine max (Linn.) Merr).

Split-plot experiment design was used in the trial. The plots $(2 \mathrm{~m} \times 3.5 \mathrm{~m})$ were separated by $50-\mathrm{cm}$-wide borders, and each treatment had 3 plots replications. All experimental treatments was irrigated at 10-12 d intervals three times before winter and four times before flowering. The total irrigation amount in treatment was $3937.5 \mathrm{~m}^{3} / \mathrm{hm}^{2}$. Therefore, the three experimental groups involved in this study were all carried out under the condition of no irrigation after anthesis.) After the flowering, stopped irrigation till the ripening stage, rainshelters were used to prevent precipitation from affecting the drought treatments. The relative soil moisture content was measured at 
$15.7 \%, 13.8 \%, 12.3 \%, 11.1 \%, 9.7 \%, 8.6 \%$, and $7.5 \%$ for $5,10,15,20,25,30$, and 35 DPA, respectively. The relative soil moisture content at harvest was $6.6 \%$. Three treatments began on the ninth day of post anthesis drought and were continued for 7 consecutive days. The control treatment (CK) was sprayed with $0.1 \%(\mathrm{v} / \mathrm{v})$ ethanol and $0.1 \%(\mathrm{v} / \mathrm{v})$ Tween20 solution; the cobalt nitrate treatment $(\mathrm{CN})$ was sprayed with $5 \times 10^{-5} \mathrm{~mol} / \mathrm{L}$ cobalt nitrate (ACC synthesis inhibitor) containing $0.1 \%(\mathrm{~V} / \mathrm{V}$ ) ethanol and $0.1 \%(\mathrm{~V} / \mathrm{V}$ ) Tween 20; and the fluridone treatment (FU) was sprayed with $2 \times 10^{-5} \mathrm{~mol} / \mathrm{L}$ of fluridone (ABA synthesis inhibitor) containing $0.1 \%(\mathrm{~V} / \mathrm{V}$ ) ethanol and $0.1 \%$ (V/V) Tween20 solution. Each treatment spraying amount was $800 \mathrm{ml} / \mathrm{m}^{2}$ in the ear of wheat began at 9 DPA and continued for 7 days. Relative water content of soil

Soil samples were taken from $0 \sim 40 \mathrm{~cm}$ soil layer by soil auger, placed in aluminum box, and measured by drying method, and the relative soil water content $=($ fresh soil weight - dry soil weight $) /$ dry soil weight $\times 100 \%$.

\section{Sampling}

Grain samples were collected from the middle region of the wheat spikes at 5, 10, 15, 20, 25, 30, and 35 DPA. Half of the kernels were frozen in liquid $\mathrm{N}$ for $5 \mathrm{~min}$ and then stored at $-80^{\circ} \mathrm{C}$. One part of the grains was fixed in $4 \%$ paraformaldehyde (ph7.2) solution to observe the ultrastructure of endosperm cells, and the other part was fixed in $2.0 \%$ glutaraldehyde (ph7.2) solution to examine the morphology of endosperm nuclei. The remaining grains were stored at $105^{\circ} \mathrm{C}$ for $30 \mathrm{~min}$ to deactivate the enzymes and then stored at $80^{\circ} \mathrm{C}$ to constant weight.

\section{Logistic model statistical method}

The grain-filling process was assessed by fitting using the Logistic growth equation $\left(y=k /\left(1+a e^{-b t}\right)\right)$. The grouting rate equation and various secondary parameters are derived from the Logistic model. In the formula, $y$ is the grain weight, $t$ is the number of days post anthesis, $k$ is the theoretical maximum grain weight, both $a$ and $b$ are undetermined coefficients. Curve Expert 1.3 software was used to obtain the grain-filling logistic equation and parameters $k$, a, and $b$.

The grain filling rate equation was obtained analytically as the first derivative of logistic curve $\left(v=d y / d t=k a b e^{-b t} /\left(1+a e^{-b t}\right)^{2}\right)$. When the first derivative of the grain filling rate equation is equal to $0, t=(\operatorname{lna}) / b$. The grain filling rate reaches a maximum at $T_{\max }=(\operatorname{lna}) / b$, therefore the maximum grain filling rate, $\mathrm{V}_{\max }=\left(\mathrm{bY} \mathrm{max}_{\max }\right)\left(1-\mathrm{Y}_{\max } / \mathrm{k}\right)$. If the second derivative of the grain filling rate equation is equal to zero, two key nodes $\left(t_{1}=(\operatorname{lna}-1.317) / b, t_{2}=(\operatorname{Ina}+1.317) / b\right)$ of the grain filling rate will be obtained. The effective grouting period is the time used when the grain weight reaches $99 \% \square \mathrm{t}_{3}=(\operatorname{lna}+4.59512) / \mathrm{C}$. The grain weights increased in the early, middle and end stages are represented by $Y_{1}, Y_{2}$, and $Y_{3}$ respectively. The average rate of the early, middle and end stages is represented by $V_{1}, V_{2}$, and $V_{3}$ respectively. The duration of the early, middle and end stages are represented by $T_{1}, T_{2}$, and $T_{3}$ respectively. Active grouting period (the time it takes to complete $90 \%$ of the total accumulation), $P=6 / b$.

\section{Cell staining}

We modified the staining method from Young ${ }^{33}$. Wheat grains were cut crosswise into $3 \mathrm{~mm}$ thick slices with a razor blade and placed in an aqueous solution containing $0.1 \%$ Evan's Blue for $2 \mathrm{~min}$ and then washed with water for $30 \mathrm{~min}$. The slices were placed on slides and photographed with a stereomicroscope (Zeiss Discovery V20, Germany).

\section{DAPI staining and fluorescent observation}

The method for making a paraffin section was described by Zhang ${ }^{80}$. Dewaxed glass slides containing grain tissues were stained with DAPI (4', 6-diamidino-2-phenylindole, $1 \mu \mathrm{g} \mathrm{ml}^{-1}$ ), and photographed with a fluorescent microscope (Zeiss Discovery V20, Germany). The stained nucleus showed blue fluorescence with UV light at wavelengths of $308 \mathrm{~nm}$.

\section{Ultra-thin slices}

The method for making a ultra-thin slices was modified from ${ }^{27}$. Ultra-thin slices (60 nm thick) were cut with an LKB-2188 ultramicrotome and then stained with uranyl acetate and alkaline lead citrate. The ultra-thin slices were photographed with a JEMTEM $100 \mathrm{CX}$ II transmission electron microscope.

\section{Determination of cell nuclei number in endosperm}

The grains (the embryo and pericarp had been removed) was fixed in Carnoy's Fluid for $4 \mathrm{~h}$ and stored in $70 \%$ ethanol. Determination of the number of endosperm nuclei according to the method of Singh and Jenner in $1982^{81}$. 


\section{DNA hydrolases activity}

DNA hydrolases activity was determined according to the method described by Young ${ }^{32}$. The absorbance was measured with a UV spectrophotometer (HITACHI-U5100). The enzyme activity was calculated by calculating the difference in absorbance $(260 \mathrm{~nm})$ between incubated and non-incubated samples. The activity $\left(\mathrm{mg}^{-1}\right.$ protein $\left.\mathrm{h}^{-1}\right)$ represents the average of three independent assays.

\section{Assay of grain total DNA}

Total grain DNA was determined using a modification of the method described by $\mathrm{Li}^{27}$.

\section{Determination of ACC content}

Wheat grains was ground into powder with a mortar and pestle in liquid nitrogen. Each sample $(4 \mathrm{~g})$ was transferred to $15 \mathrm{ml}$ screw-cap tubes. $9 \mathrm{ml}$ of phosphate buffer ( $\mathrm{pH}=7.2-7.4)$ was added and mixed with an oscillator. After centrifugation (4,000 rpm, $20 \mathrm{~min})$, the supernatant was collected. The double antibody sandwich elisa kit (Shanghai Enzyme-linked Biotechnology Co., Ltd. China) was used for the determination of ACC content. The specific steps were carried out according to the instructions.

\section{Determination of ABA content}

ABA content was measured using a modification of the method described by ${ }^{82}$. Wheat grains was ground into powder with a mortar and pestle in liquid nitrogen. Four gram of powder was transferred to $50 \mathrm{ml}$ screw-cap tubes. $16 \mathrm{ml}$ (the volume of sample and extraction buffer remained 1:4) was added to extract buffer solution (isopropanol: water: concentrated hydrochloric acid $=2: 1: 0.002$ $\mathrm{mol} / \mathrm{L}$ butylated hydroxytoluene as antioxidant), and oscillated at $4^{\circ} \mathrm{C}$ for $200 \mathrm{rpm}$ for $30 \mathrm{~min}$. Then $32 \mathrm{ml}(2$ times of the extraction buffer) dichloromethane was added to oscillate at $4^{\circ} \mathrm{C} 200 \mathrm{rpm}$ for $30 \mathrm{~min}$. After centrifugation $\left(12,000 \mathrm{rpm}, 10 \mathrm{~min}, 4^{\circ} \mathrm{C}\right)$, the clear liquid was removed to avoid light and blow dry with nitrogen gas. The samples constant volume with methanol to 2 ml. The solution was filtered through a $0.45 \mu \mathrm{m}$ microporous membrane and analyzed by HPLC. HPLC separation was performed on a zorbaxSB-C18 $(150 \times 4.6 \mathrm{~mm}, 5 \mathrm{~m})$ reversed-phase column at a temperature of $26^{\circ} \mathrm{C}$. The detector wavelength was $262 \mathrm{~nm}$. And the mobile phase was methanol: $0.2 \%$ acetic acid aqueous solution (38:62). The flow rate was $1 \mathrm{ml} / \mathrm{min}$.

\section{Detection of relative expression of genes involved in ethylene and PCD. Designation of primers}

Primers for the genes were designed by Primer5.0. software based on the sequences of ers1, ers2, etr1, etr2 and dad1 genes published in the National Center for Biotechnology Information (NCBI, https://www.ncbi.nlm.nih.gov/), and then the primers were synthesized by Shenggong Biotech (Shanghai) Co., Ltd. The wheat actin gene (NCBI No. DN551593) was used as the marker gene. The specificity of the primers was verified by gradient PCR while optimizing the PCR conditions. The primer sequences are shown in table 1.

\section{RNA extraction and cDNA synthesis}

Fresh samples stored in a $-80^{\circ} \mathrm{C}$ refrigerator were ground with liquid nitrogen, and then RNA from the samples was extracted using Fruitmate (Takara, Cat\#9192, Japan) and RNAiso plus (Takara, Cat\#9108, Japan) kits according to the instructions. The integrity of the RNA was examined by agarose gel electrophoresis. cDNA was synthesized using the TIANScript cDNA First Strand Synthesis Kit (Tiangen, Cat\#KR104-02, China), and the quality of cDNA was checked by amplifying the actin gene.

\section{Quantitative Real-time PCR}

The amplification of target gene was detected on a real-time quantitative fluorescence PCR instrument (Roche Light Cycler 480 II, USA) using a SYBR Green I Master kit (Roche, Cat\#06924204001, USA), according to the instructions with three replications.

\section{Statistical analysis and image processing}

Statistical analyses of all data were performed using Origin software v. 8.0 and SPSS 13.0 software. The relative quantification was calculated with the following formulae:

$\triangle \mathrm{Ct}$ (target gene) $=\mathrm{Ct}($ target gene) $-\mathrm{Ct}($ actin of the same sample) $(1)$

Relative quantification $=2^{-\triangle \mathrm{Ct}}($ target gene) $(2)$ 


\section{Abbreviations}

ABA Abscisic acid

ACC 1-Aminocyclopropane-1-carboxylic acid

CK Control treatment

$\mathrm{CN}$ Cobalt nitrate treatment

DAPI 4',6-diamidino-2-phenylindole

DNase Deoxyribonuclease

DPA Days post anthesis

FU Fluridone treatment

PCD Programmed cell death

\section{Declarations}

\section{Acknowledgements}

This study was financially supported by the National Natural Science Foundation of China (31860337ه31860335, 31360292, 31560389), New Cultivar Breeding and Germplasm Enhancement of Wheat (2016AC027), Young Innovator Cultivating Project of Shihezi University (CXRC201703), and Specific Project for Breeding of Shihezi University (YZZX202002).

\section{Author information}

\section{Affiliations}

College of Agriculture/The Key Laboratory of Oasis Eco-agriculture, Xinjiang Production and Construction Group,Shihezi University, Shihezi, Xinjiang 832000, P.R. China

Li Chao, Zhang Xiangchi®Fu Kaiyong, Li Chunyan, Li Cheng

Agricultural and rural Bureau ,Tekes County ,Bureaulli Kazak Autonomous Prefecture,Xinjiang 835500, P.R. China

Wenting Guo

\section{Authors contributions}

C.L. performed experiments, analysed data and wrote the paper. X-C.Z, W-T. G., K-Y. F. performed experiment. C.L. and C-Y.L edited the manuscript. All authors approved the final version.

\section{Corresponding author}

Correspondence to Li Chunyan and Li Cheng

\section{Ethics declarations}

\section{Conflict of interest}

We declare that we have no financial and personal relationships with other people or organizations that can inappropriately influence our work, there is no professional or other personal interest of any nature or kind in any product, service and/or company that could be construed as influencing the position presented in, or the review of, the manuscript entitled.

\section{References}


1. Nikitina, E., Kuznetsova, V., Kroupin, P., Karlov, G. \& Divashuk, M. Development of specific thinopyrum cytogenetic markers for wheat-wheatgrass hybrids using sequencing and qPCR data. Int. J. Mol. Sci, 21 (12), 4495 (2020).

2. Puttamadanayaka, S., Harikrishna, Balaramaiah, M., Biradar, S. \& Prabhu, K. Mapping genomic regions of moisture deficit stress tolerance using backcross inbred lines in wheat (Triticum aestivum L.). Sci. Rep-UK, 10, 1 (2020).

3. Leng, G. \& Jim, H. Crop yield sensitivity of global major agricultural countries to droughts and the projected changes in the future. Sci. Total. Environ, 654, 811-821 (2019).

4. Szegletes, Z., Erdei, L., Tari, I. \& Cseuz, L. Accumulation of osmoprotectants in wheat cultivars of different drought tolerance. Cereal Res. Commun, 28 (4), 403-410 (2000).

5. Zhu, J. K. Salt and drought stress signal transduction in plants. Annu Rev Plant Biol, 53 (1), $247-273$ (2002).

6. Pradhan, G. P., Prasad, P. V. V., Fritz, A. K., Kirkham, M. B. \& Gill, B. S. Effects of drought and high temperature stress on synthetic hexaploid wheat. Funct. Plant Biolo, 39 (3), 190-198 (2012).

7. Reynolds, M. P., Mujeeb, K. A. \& Sawkins, M. Prospects for utilising plant-adaptive mechanisms to improve wheat and other crops in drought-and salinity-prone environments. Ann. Appm. Biol, 146 (2), 239-259 (2015).

8. Kosová, K., Urban, M. O., Vítámvás, P. \& Práil, I. T. Drought Stress Response in Common Wheat, Durum Wheat, and Barley: Transcriptomics, Proteomics, Metabolomics, Physiology, and Breeding for an Enhanced Drought Tolerance. Berlin: Springer International Publishing. 2: 277-314(2016).

9. Loss, S. P. \& Khm, S. Morphological and physiological traits associated with wheat yield increases in Mediterranean environments. Adv. Agron, 52 (08), 229-276 (1994).

10. Araus, J. L., Slafer, G. A., Reynolds, M. P. \& Royo, C. Plant Breeding and Drought in Câ,fCereals: What Should We Breed For? Ann. Bot. Fenn, 89 (7), 925-940 (2002).

11. Turner, N. C. Sustainable production of crops and pastures under drought in a Mediterranean environment. Ann. Appl. Biol, 144 (2), 139-147 (2004).

12. Kobata, T., Palta, J. A. \& Turner, N. C. Rate of Development of Postanthesis Water Deficits and Grain Filling of Spring Wheat. Crop Sci, 32 (5), 1238-1242 (1992).

13. Yang, J., Zhang, J., Liu, K., Wang, Z. \& Liu, L. Abscisic acid and ethylene interact in wheat grains in response to soil drying during grain filling. New. Phytol, 171 (2), 293-303 (2006).

14. Farooq, M., Hussain, M. \& Siddique, K. H. M. Drought Stress in Wheat during Flowering and Grain-filling Periods. Crit. Rev. Plant Sci, 33 (4), 331-349 (2014).

15. Olivaresvillegas, J. J., Reynolds, M. P. \& Mcdonald, G. K. Drought-adaptive attributes in the Seri/Babax hexaploid wheat population. Funct. Plant Biol, 34 (3), 189-203 (2007).

16. Cai, G. et al. D. Polyamines are common players in different facets of plant programmed cell death. Amino Acids, 47 (1), $27-44$ (2015).

17. Gadjev, I., Stone, J. M. \& Gechev, T. S. Programmed Cell Death in Plants: New Insights into Redox Regulation and the Role of Hydrogen Peroxide. Int. Rev. Cell Mol. Biol, 270, 87-144 (2008).

18. Fukuda, H. Programmed cell death of tracheary elements as a paradigm in plants. Plant Mol. Biol, 44 (3), 245 (2000).

19. Xie, Y. et al. Hydrogen sulfide delays GA-triggered programmed cell death in wheat aleurone layers by the modulation of glutathione homeostasis and heme oxygenase-1 expression. J. Plant Physiol, 171 (2), 53-62 (2014).

20. Cao, M. \& Li, X. Die for living better: plants modify root system architecture through inducing PCD in root meristem under severe water stress. Plant Signal Behav, 5 (12), 1645-1646 (2010).

21. Li, C. et al. Effects of drought on the morphological and physicochemical characteristics of starch granules in different elite wheat varieties. J. Cereal Sci, 6 (6), 66-73 (2015).

22. Olsen, O. A. Endosperm Developments. Curr Opin Plant Biol, 10 (4), 485-488 (1998).

23. Fan, H. Y. et al. Effects of waterlogging on amyloplasts and programmed cell death in endosperm cells of Triticum aestivum L. Protoplasma, 250, 1091-1103 (2013).

24. Cheng, X. X. et al. Reactive oxygen species regulate programmed cell death progress of endosperm in winter wheat (Triticum aestivum L.) under waterlogging. Protoplasma, 253, 311-327 (2016).

25. Panda, S. K., Yamamoto, Y., Kondo, H. \& Matsumoto, H. Mitochondrial alterations related to programmed cell death in tobacco cells under aluminium stress. C. R. Biol, 331 (8), 597-610 (2008).

Page $11 / 16$ 
26. Chen, X. et al. Mitochondrial proteome during salt stress-induced programmed cell death in rice. Plant Physiol. Biochem, 47 (5), 407-415 (2009).

27. Li, C. et al. Programmed cell death in wheat (Triticum aestivum L.) endosperm cells is affected by drought stress. Protoplasma, 255 (4), 1039-1052 (2018).

28. Fernando, D. \& Cejudo, F. Programmed cell death (PCD): An essential process of cereal seed development and germination. Front. Plant Sci, 5 (e51435), 366 (2014).

29. Wolters, H. \& Jürgens, G. Survival of the flexible: hormonal growth control and adaptation in plant development. Nat. Rev. Genet, 10 (5), 305 (2009).

30. Dubois, M., Broeck, L. V. \& Inzé, D. The Pivotal Role of Ethylene in Plant Growth. Trends Plant Sci, 23 (4), 311-323 (2018).

31. Ueda, H. et al. Genetic interaction among phytochrome, ethylene and abscisic acid signaling during dark-induced senescence in Arabidopsis thaliana. Front. Plant Sci, 11, 564 (2020).

32. Young, T. E., Gallie, D. R. \& Demason, D. A. Ethylene-mediated programmed cell death during maize endosperm development of wildtype and shrunken2 genotypes. Plant Physiol, 115 (2), 737-751 (1997).

33. Young, T. E. \& Gallie, D. R. Analysis of programmed cell death in wheat endosperm reveals differences in endosperm development between cereals. Plant Mol. Biol, 39 (5), 915-926 (1999).

34. Sreenivasulu, N. et al. Gene expression patterns reveal tissue-specific signaling networks controlling programmed cell death and ABA-regulated maturation in developing barley seeds. Plant J, 47 (2), 310-327 (2010).

35. Betake, P. C., Lonsdale, J. E. \& Jones, F. R. L. Hormonally regulated programmed cell death in barley aleurone cells. Plant Cell, 11 (6), 1033-1045 (1999).

36. Clifford, P. E., Offler, C. E. \& Patrick, J. W. Growth Regulators Have Rapid Effects on Photosynthate Unloading from Seed Coats of Phaseolus vulgaris L. Plant Physiol, 80 (3), 635-637 (1986).

37. Gayler, K. R. \& Glasziou, K. T. Plant enzyme synthesis: Hormonal regulation of invertase and peroxidase synthesis in sugar cane. Planta, 84 (2), 185-194 (1968).

38. Guan, Y. et al. Transcriptome analysis reveals important candidate genes involved in grain-size formation at the stage of grain enlargement in common wheat cultivar "Bainong 4199".Plos One.14(3) (2019).

39. Liu, K., Yu, X., Cheng, T., Wang, Z. Q. \& Yang, J. C. Responses of ethylene and ACC in rice grains to soil moisture and their relation to grain filling. Front Agr Chin, 2 (2), 172-180 (2008).

40. Rook, F. et al. Impaired sucrose-induction mutants reveal the modulation of sugar-induced starch biosynthetic gene expression by abscisic acid signaling. Plant J, 26, 421-433 (2001).

41. Mohapatra, P., Naik, P. \& Patel, R. Ethylene inhibitors improve dry matter partitioning and development of late flowering spikelets on rice panicles. Australian Journal of Plant Physiology, 27, 311-323 (2000).

42. Naik, P. \& Mohapatra, P. Ethylene inhibitors enhanced sucrose synthase activity and promoted grain filling of basal rice kernels. Australian Journal of Plant Physiology, 27, 997-1008 (2000).

43. Yang, J. et al. Correlation of cytokinin levels in the endosperm and roots with cell number division activity during endosperm development in rice. Annals of Botany, 90, 369-377 (2002).

44. Bollmark, M. \& Eliasson, L. Ethylene accelerates the breakdown of cytokinin and thereby stimulates rooting in norway spruce hypocotyl cuttings. Physiolo Plantarum, 80, 534-540 (1990).

45. Bhowmik, P. K. \& Matsui, T. Ethylene biosynthetic genes in 'Moso' bamboo shoot in response to wounding. Postharvest Biol. Tec, 38 (2), 188-194 (2005).

46. Dupille, E. \& Zacarías, L. Extraction and biochemical characterization of wound-induced ACC oxidase from Citrus peel. Plant Sci, 114 (1), 53-60 (1996).

47. Masaya, K., Yoshitaka, H. \& Hiroshi, H. Wound-Induced Ethylene Synthesis and Expression and Formation of 1-Aminocyclopropane1-Carboxylate (ACC) Synthase, ACC Oxidase, Phenylalanine Ammonia-Lyase, and Peroxidase in Wounded Mesocarp Tissue of Cucurbita maxima. Plant Cell Physiol, 4, 440-447 (2000).

48. Adams, D. \& Yang, S. Ethylene biosynthesis: Identification of 1-aminocyclopropane-1-carboxylic acid as an intermediate in the conversion of methionine to ethylene. Pnatl. Acad. Sci. USA, 76 (1), 170-174 (1979).

49. Rantong, G. R., Evans, R. \& Gunawardena, A. H. Lace plant ethylene receptors, AmERS1a and AmERS1c, regulate ethylene-induced programmed cell death during leaf morphogenesis. Plant Mol. Biol, 89 (3), 215-227 (2015).

Page 12/16 
50. Overmyer, K. et al. Ozone-Sensitive Arabidopsis rcd1 Mutant Reveals Opposite Roles for Ethylene and Jasmonate Signaling Pathways in Regulating Superoxide-Dependent Cell Death. Plant Cell, 12 (10), 1849-1862 (2000).

51. Tambussi, E. A., Bartoli, C. G., Beltrano, J., Guiamet, J. J. \& Araus, J. L. Oxidative damage to thylakoid proteins in water-stressed leaves of wheat (Triticum aestivum L.). Physiol. Plant, 108 (4), 398-404 (2010).

52. Chen, C. T. \& Kao, C. H. Senescence of rice leaves 32. Effects of abscisic-acid and benzyladenine on polyamines and ethylene production during senescence. J. Plant Physiol, 139 (5), 617-620 (1992).

53. Yu, J., Yu, J., Liao, W., Xie, J. \& Wu, Y. Ethylene was Involved in $\mathrm{Ca}^{2+}$-Regulated $\mathrm{Na}^{+}$Homeostasis, $\mathrm{Na}^{+}$Transport and Cell Ultrastructure During Adventitious Rooting in Cucumber Explants Under Salt Stress.J. Plant Biol. (3) (2020).

54. Hall, B. P., Shakeel, S. N. \& Schaller, G. E. Ethylene Receptors: Ethylene Perception and Signal Transduction. J. Plant Growth Regul, 26 (2), 118-130 (2007).

55. Apelbaum, A. \& Yang, S. F. Biosynthesis of Stress Ethylene Induced by Water Deficit. Plant Physiol, 68 (3), $594-596$ (1981).

56. Beltrano, J., Ronco, M. G. \& Montaldi, E. R. Drought Stress Syndrome in Wheat Is Provoked by Ethylene Evolution Imbalance and Reversed by Rewatering, Aminoethoxyvinylglycine, or Sodium Benzoate. J. Plant Growth Regul, 18 (2), 59-64 (1999).

57. Habben, J. E. et al. Transgenic alteration of ethylene biosynthesis increases grain yield in maize under field drought-stress conditions. Plant Biotechnol J, 12 (6), 685-693 (2014).

58. Lee, S. C. \& Luan, S. ABA signal transduction at the crossroad of biotic and abiotic stress responses. Plant Cell Environ, 35 (1), $53-$ 60 (2011).

59. Young, T. E. \& Gallie, D. R. Regulation of programmed cell death in maize endosperm by abscisic acid. Plant Mol. Biol, 42 (2), 397414 (2000).

60. Nguyen, H. N., Sabelli, P. A. \& Larkins, B. A. Endoreduplication and Programmed Cell Death in the Cereal Endosperm. Endosperm, 8 , 21-43 (2007).

61. Anderson, J. P. et al. Antagonistic interaction between abscisic acid and jasmonate-ethylene signaling pathways modulates defense gene expression and disease resistance in Arabidopsis. Plant cell, 16 (12), 3460-3479 (2004).

62. Tanaka, Y. et al. Ethylene inhibits abscisic acid-induced stomatal closure in Arabidopsis. Plant. Physiol, 138 (4), $2337-2343$ (2005).

63. Wang, M. et al. Spatial and temporal regulation of DNA fragmentation in the aleurone of germinating barley. J. Exp. B, 49 (325), 1293-1301 (1998).

64. Qin, S. J. et al. Abscisic acid and aldehyde oxidase activity in maize ear leaf and grain relative to post-flowering photosynthetic capacity and grain-filling rate under different water/nitrogen treatments. Pant Physiol. Bioch, 70, 69-80 (2013).

65. Zheng, P. et al. Programmed cell death of secretory cavity cells of citrus fruits is associated with Ca2+ accumulation in the nucleus. Trees, 28 (4), 1137-1144 (2014).

66. Qi, Y. H. et al. The release of cytochrome $\mathrm{c}$ and the regulation of the programmed cell death progress in the endosperm of winter wheat (Triticum aestivum L.) under waterlogging. Protoplasma, 255 (6), 1651-1665 (2018).

67. Jones, A. Does the plant mitochondrion integrate cellular stress and regulate programmed cell death? Trends Plant Sci, 5 (5), 225230 (2000).

68. Sadiqov, S. T., Akbulut, M. \& Ehmedov, V. Role of Ca2+ in drought stress signaling in wheat seedlings. Biochemistry, 67 (4), $491-$ 497 (2002).

69. Ning, S. B., Wang, L. \& Jin, W. W. Expression of Dad1 in Maize Development. Reprod. Bio, 10 (2), 53-60 (2001).

70. Bao, Y., Mei, Y. Q., Xu, X., Liu, Y. \& Wu, Z. Changes in the promoter of a defender against apoptotic cell death gene affect its expression in upland cotton.J. Syst. Evol. (2020).

71. Yan, Q. et al. GmDAD1, a conserved defender against cell death 1 (DAD1) from soybean, positively regulates plant resistance against phytophthora pathogens. Front. Plant Sci, 10, 107 (2019).

72. Zeng, Z. et al. Endopolyploidy levels in barley vary in different root types and significantly decrease under phosphorus deficiency. Plant Physiol Biochem, 118, 11-21 (2017).

73. Bringezu, T. \& Weber, W. Dry matter, DNA content and endopolyploidy of maize cultivars from different maturity groups in field experiments. Annals of Biology, 31 (1), 1-12 (2015).

74. Li, S. et al. The distribution pattern of endopolyploidy in maize. Theor. Appl. Genet, 132, 1487-1503 (2019).

75. Barow, M. Endopolyploidy in seed plants. Bio. Essays, 28 (3), 271-281 (2010).

Page 13/16 
76. Lur, H. S. \& Setter, T. L. Role of Auxin in Maize Endosperm Development (Timing of Nuclear DNA Endoreduplication, Zein Expression, and Cytokinin). Plant Physiol, 103 (1), 273-280 (1993).

77. Castellano, M. M., Boniotti, M. B., Schnittge, C. A. \& Gutierrez, C. D. N. A. Replication Licensing Affects Cell Proliferation or Endoreplication in a Cell Type-Specific Manner. Plant Cell, 16 (9), 2380-2393 (2004).

78. Juan, C. P., Sara, D. T., Nerea, C. \& Crisanto, G. The balance between cell division and endoreplication depends on E2FC-DPB, transcription factors regulated by the ubiquitin-SCFSKP2A pathway in arabidopsis. Plant Cell, 18 (9), 2224-2235 (2006).

79. Wang, H., Zhou, Y. \& Fowke, L. C. The emerging importance of cyclin-dependent kinase inhibitors in the regulation of the plant cell cycle and related processes. Can. J. Bot, 84 (4), 640-650 (2006).

80. Zhang, R. Q., Li, C., Fu, K. Y., Li, C. \& Li, C. Y. An improved method for studying whole sections of late developing wheat grain. Biotech Histochem, 93 (7), 1-7 (2018).

81. Singh, B. K. \& Jenner, C. F. A modified method for the determination of cell number in wheat endosperm. Plant Sci. Lett, 26 (2-3), 273-278 (1982).

82. Wu, J. et al. An integrative analysis of the transcriptome and proteome of the pulp of a spontaneous late-ripening sweet orange mutant and its wild type improves our understanding of fruit ripening in citrus. J. Exp. Bot, 65 (6), 1651-1671 (2014).

\section{Tables}

Table.1 Characteristics of primers used to measure differential gene expression using Quantitative PCR

\begin{tabular}{|c|c|c|c|c|c|}
\hline Gene & Genbank number & Upstream primer $\left(5^{\prime}-3^{\prime}\right)$ & Downstream primer $\left(5^{\prime}-3^{\prime}\right)$ & Tm value $\rrbracket^{\circ} \mathrm{C} \rrbracket$ & Size $\ b p \rrbracket$ \\
\hline ers1 & FJ628419.1 & TCTTCACCTACGAGCCCCATT & TTCTCCCTGACCTTGACCCT & $60^{\circ} \mathrm{C}$ & 142 \\
\hline ers2 & HM601437.2 & TGCCCTGGATTTAGCTCGAC & CTGCTCAGGGGTGAGTTCAG & $59^{\circ} \mathrm{C}$ & 151 \\
\hline etr1 & KJ001485.1 & GAGCTCGATTGGGAGATGGG & GCACACTCTTCCAGACCCAA & $59^{\circ} \mathrm{C}$ & 158 \\
\hline etr2 & JX046068.1 & ACCGCCCTCGTCTCCTTC & GCCTCCTCCTGCCTCTTCA & $62^{\circ} \mathrm{C}$ & 146 \\
\hline dad1 & HM447647.1 & CGCCCACGAATCTCAAG & ATACGGAGGCAAACACC & $62^{\circ} \mathrm{C}$ & 148 \\
\hline
\end{tabular}

Table. 2 The parameters of grain-filling characteristics in wheat under different treatments.

\begin{tabular}{|c|c|c|c|c|c|c|c|c|c|}
\hline Treatment & Fitting equeation & $\mathrm{R}^{2}$ & $\mathrm{~K}(\mathrm{~g})$ & $\begin{array}{l}\mathrm{V}_{\max } \\
(\mathrm{g} / \mathrm{d} \cdot \text { kernel })\end{array}$ & $\begin{array}{l}T_{\max } \\
\text { (d) }\end{array}$ & $\begin{array}{l}Y_{\max } \\
(\mathrm{g})\end{array}$ & $\begin{array}{l}\mathrm{V}_{\text {mean }} \\
(\mathrm{g} / \mathrm{d} \cdot \text { kernel })\end{array}$ & $\begin{array}{l}P \\
\text { (d) }\end{array}$ & $\begin{array}{l}\text { t3 } \\
\text { (d) }\end{array}$ \\
\hline CK & $y=48.54 /\left(1+79.95 e^{-0.222 x}\right)$ & 0.999 & $48.5^{\mathrm{b}}$ & $2.69^{a}$ & $19.7^{\mathrm{b}}$ & $24.27^{b}$ & $1.19^{a}$ & $27^{b}$ & $40.4^{b}$ \\
\hline $\mathrm{CN}$ & $y=52.12 /\left(1+55.28 e^{-0.198 x}\right)$ & 0.999 & $52.12^{\mathrm{a}}$ & $2.58^{b}$ & $20.3^{a}$ & $26.06^{a}$ & $1.19^{a}$ & $30.3^{a}$ & $43.5^{\mathrm{a}}$ \\
\hline FU & $y=43.9 /\left(1+62.59 e^{-0.226 x}\right)$ & 0.999 & $43.9^{c}$ & $2.48^{c}$ & $18.3^{\mathrm{c}}$ & $21.95^{\mathrm{c}}$ & $1.12^{\mathrm{b}}$ & $26.5^{\mathrm{b}}$ & $38.6^{\circ}$ \\
\hline
\end{tabular}

Note: $\mathrm{V}_{\text {max }}$ : maximum grain-filling rate; $\mathrm{T}_{\max }$ : the time reaching the maximum grain-filling rate; $\mathrm{Y}_{\max }$ : grain weight at the time of maximum grain-filling rate; $V_{\text {mean }}$ : mean grain-filling rate; $P$ : active grain-filling period; $t 3$ : effective grain-filling time; $P$ : active grain-filling period. $a, b, c$ represent the significant comparison between different treatments of the same indicator at $\mathrm{P}<0.05$ levels.

Table. 3 The parameters characteristics of the three grain-filling phases in wheat under different treatment conditions 


\begin{tabular}{|c|c|c|c|c|}
\hline Filling phase & Parameters & CK & $\mathrm{CN}$ & FU \\
\hline \multirow[t]{3}{*}{ Early stage } & $\mathrm{T} 1(\mathrm{~d})$ & $13.8^{\mathrm{a}}$ & $13.61^{\mathrm{a}}$ & $12.48^{\mathrm{b}}$ \\
\hline & $\mathrm{V}_{1}\left(\mathrm{gd}^{-1} \cdot \mathrm{kernel}^{-1}\right)$ & $0.74^{\mathrm{b}}$ & $0.81^{a}$ & $0.74^{\mathrm{b}}$ \\
\hline & $Y_{1}\left(g \cdot\right.$ kernel $\left.^{-1}\right)$ & $10.26^{\mathrm{b}}$ & $13.61^{a}$ & $9.28^{c}$ \\
\hline \multirow[t]{3}{*}{ Middle stage } & $\mathrm{T} 2(\mathrm{~d})$ & $11.86^{\mathrm{b}}$ & $13.3^{\mathrm{a}}$ & $11.65^{b}$ \\
\hline & $\mathrm{V}_{2}\left(\mathrm{gd}^{-1} \cdot\right.$ kernel $\left.^{-1}\right)$ & $2.36^{a}$ & $2.26^{b}$ & $2.17^{c}$ \\
\hline & $\mathrm{Y}_{2}\left(\mathrm{~g} \cdot\right.$ kernel $\left.^{-1}\right)$ & $28.03^{\mathrm{b}}$ & $30.09^{a}$ & $25.34^{c}$ \\
\hline \multirow[t]{3}{*}{ Late stage } & $\mathrm{T} 3(\mathrm{~d})$ & $14.77^{b}$ & $16.56^{\mathrm{a}}$ & $14.5^{\mathrm{b}}$ \\
\hline & $\mathrm{V}_{3}\left(\mathrm{gd}^{-1} \cdot\right.$ kernel $\left.^{-1}\right)$ & $0.66^{a}$ & $0.64^{a}$ & $0.60^{b}$ \\
\hline & $Y_{3}\left(g \cdot\right.$ kernel $\left.^{-1}\right)$ & $9.77^{\mathrm{b}}$ & $10.49^{a}$ & $8.83^{c}$ \\
\hline
\end{tabular}

Note: $T_{1}$ : grain-filling duration of early stage; $V_{1}$ : mean grain-filling rate of early stage; $Y_{1}$ : increased grain weight of early stage; $T_{2}$ : grain-filling duration of middle stage; $\mathrm{V}_{2}$ : mean grain-filling rate of middle stage; $\mathrm{Y}_{2}$ : increased grain weight of middle stage; $T_{3}$ : grainfilling duration of late stage; $V_{3}$ : mean grain-filling rate of late stage; $Y_{3}$ : increased grain weight of late stage; $a, b, c$ represent the significant comparison between different treatments of the same indicator at $\mathrm{P}<0.05$ levels.

Table. 4 Correlation analysis of DNA content, ABA content and grain-filling rate of wheat grain under different treatments.

\begin{tabular}{lllllll} 
& \multicolumn{2}{l}{ grain-filling rate } & \multicolumn{3}{l}{ ABA content } \\
\cline { 2 - 7 } & CK & CN & FU & CK & CN & FU \\
\hline DNA content & $0.892^{\star \star}$ & $0.937^{\star \star}$ & $0.897^{\star \star}$ & $0.852^{\star}$ & $0.829 *$ & $0.852^{\star}$ \\
\hline ABA content & $0.793^{\star}$ & $0.918^{\star \star}$ & $0.964^{\star \star}$ & 1 & &
\end{tabular}

Note: The figures in the table are the correlation coefficient, * and * * represent the difference of 0.05 and 0.01 levels respectively.

\section{Figures}

\section{Figure 1}

Grain weight at different treatments. The $x$-axis represents days post anthesis. The $y$-axis represents the grain weight. Error bars were calculated based on three independent experiments. Each data point is the average \pm SE of three replicates. $a, b, c$ represent the significant comparison between different treatments of the same indicator at $P<0.05$ levels.

\section{Figure 2}

Viability staining of developing wheat seed under different treatments. A1-A4 were the grain endosperm cross-section treated with solvent at 10, 15, 20 and 25 DPA, respectively. B1-B4 were treated with cobalt nitrate at 10, 15, 20 and 25 DPA, respectively. C1-C4 were treated with fluridone at 10,15, 20 and 25 DPA, respectively. Cells that have undergone PCD were stained blue. DPA: Days post anthesis; SE: endosperm; P: pericarp. 


\section{Figure 3}

DAPI staining of nuclei in wheat endosperm cells. Light blue fluorescence within the cells indicates the presence of nuclear DNA. A1-A2 were treated with solvent at 25 and 30 DPA, respectively. A2-B2 were treated with cobalt nitrate at 25 and 30 DPA, respectively. A3-B3 were treated with fluridone at 25 and 30 DPA, respectively. Magnification of 150 times. White boxes indicate deformed nuclei.

\section{Figure 4}

The ultrastructural morphological changes of nucleus in wheat starchy endosperm. A1-B2 were the endosperm nuclei of the solvent treatment at 15 and 20 DPA, respectively. A2-B2 were the endosperm nuclei of cobalt nitrate treatment at 15 and 20 DPA, respectively. A3-B3 were the endosperm nuclei of fluridone treatment at 15 and 20 DPA, respectively. N: nucleus, S: starch, V: vacuole, P: protein, N: nucleus, S: starch, M: mitochondria, ER: endoplasmic reticulum, V: vacuole, CW: cell wall.

\section{Figure 5}

Number of nuclei in endosperm. The x-axis represents the days post anthesis. The y-axis represents the number of nuclei per endosperm. Error bars were calculated based on three independent experiments. Values are mean \pm Standard Error of three replications. $a, b, c$ represent the significant comparison between different treatments of the same indicator at $P<0.05$ levels.

\section{Figure 6}

DNA content and nuclease hydrolase activity in wheat endosperm cells. The $x$-axis represents the days post anthesis. The y-axis represents the DNA content in Figure 6A. The y-axis represents the DNA hydrolase activity in figure 6B. Error bars were calculated based on three independent experiments. Each data point is the average \pm SE of three replicates. $a, b, c$ represent the significant comparison between different treatments of the same indicator at $\mathrm{P}<0.05$ levels.

\section{Figure 7}

The content of ACC in wheat grain. The x-axis represents the days post anthesis. The y-axis represents the content of ACC in figure 7A. The $y$-axis represents the content of ABA in figure 7B. Error bars were calculated based on three independent experiments. Each data point is the average \pm SE of three replicates. $a, b, c$ represent the significant comparison between different treatments of the same indicator at $\mathrm{P}<0.05$ levels.

\section{Figure 8}

Relative expression of genes involved in ETH receptor and PCD during wheat grain development. The x-axis represents days post anthesis. The y-axis represents relative expression. Error bars were calculated based on three independent experiments. Each data point is the average \pm SE of three replicates. a, b, c represent the significant comparison between different treatments of the same indicator at $P<0.05$ levels. 